\title{
ANTIBACTERIAL AND ANTIOXIDANT ACTIVITY OF SAPONIN FROM ABUTILON INDICUM LEAVES
}

\section{LOKESH RAVI*, MANASVI V, PRAVEENA LAKSHMI B}

Division of Biomedical Sciences, School of Biosciences and Technology, VIT University, Vellore, Tamil Nadu, India. Email: lokesh.ravi@vit. ac.in

Received: 05 September 2016, Revised and Accepted: 19 September 2016

\section{ABSTRACT}

Objective: Aim of this study is to analyze the antibacterial and antioxidant potential of crude saponin extract (CSE) from Abutilon indicum leaves.

Methods: CSE was subjected for gas chromatography-mass spectrometry (GC-MS) analysis to identify its components. Antibacterial potential was analyzed using agar well diffusion method and minimum inhibitory concentration (MIC) was detected using 96-well plate method, against Staphylococcus aureus (MTCC: 3160) and Escherichia coli (MTCC: 443). DNA damage study was performed using comet assay. Antioxidant capability was studied using 2,2-diphenyl-1-picrylhydrazyl scavenging assay.

Results: GC-MS analysis suggested a library match to benzene-1-4-bis(phenylmethyl), with a molecular weight of 258 g/mol to be the major component in the CSE at 21.25 RT. CSE demonstrated $96.16 \%$ free radical scavenging activity at $2.5 \mathrm{mg} / \mathrm{ml}$ concentration. CSE demonstrated a significant antibacterial activity in the well diffusion assay, S. aureus $17 \mathrm{~mm}$ and E. coli $15 \mathrm{~mm}$, with a MIC value of $1.11 \mathrm{mg} / \mathrm{ml}$. Comet assay demonstrated no DNA damage.

Conclusion: These results conclude that CSE of $A$. indicum leaves possesses promising antibacterial and antioxidant potential.

Keywords: Abutilon indicum, Saponin, Escherichia coli, Staphylococcus aureus, 2,2-diphenyl-1-picrylhydrazyl, Antibacterial assay.

(C) 2016 The Authors. Published by Innovare Academic Sciences Pvt Ltd. This is an open access article under the CC BY license (http://creativecommons. org/licenses/by/4. 0/) DOI: http://dx.doi.org/10.22159/ajpcr.2016.v9s3.15064

\section{INTRODUCTION}

Medicinal plants are used since ages as remedies for human diseases as they contain numerous phytochemicals with high therapeutic value and are considered to be more natural and safe when compared to synthetic drugs [1]. One of the most useful medicinal plants is Abutilon indicum. A. indicum belongs to family Malvaceae, which is commonly called as country mallow (English), Kanghi (Hindi), and Atibala (Sanskrit) [2]. This plant is extensively grown in India, Pakistan, and Bangladesh [3]. The phytochemical analysis of $A$. indicum leaves has shown the presence of amino acids, glucose, fructose, and galactose [4] This plant has biologically active secondary metabolites which confer significant pharmacological and medicinal properties to this plant [5] This plant is used as a treatment for pharmaceutical disorders ailments for wound healing, antioxidative, antitumor, antidiabetic, antifungal, and antibacterial properties [5].

Among the various secondary metabolites such as phenols, alkaloids, and flavonoids are found in this plant, saponins have an enormous significance in pharmaceutical industry. Saponins are normally nonvolatile, and they are surface active compounds which are widely distributed in nature [5].

Saponins are secondary metabolites which are distributed along the plant kingdom. Saponin acts as a chemical barrier or such as a shield in the plant defense system to encounter the pathogens. Saponins are found in plant tissues which are mostly vulnerable to fungal or bacterial attack [6]. Saponins are hazardous but are soluble in water [7]. They contain a polycyclic aglycone that is either a choline steroid or triterpenoid attached to via C3 and ether bond to sugar side chain. The aglycone is referred to as the sapogenin and steroid saponins are called saraponins [8]. Saponins are rich in pharmaceutical properties and recently many studies focus on saponins ability to increase immune responses. They are many other properties such as antibacterial, antioxidant, anticancer, antidiabetic, and antiobesity [7]. Because of their surfactant properties, saponins are also used industrially, in mining and ore separation, emulsions for photographic films and cosmetic products such as lipstick and shampoo, where their antifungal and antibacterial properties are important in addition to their emollient effects [9]. Triterpenoid saponins have a low hormonal activity. They are often expectorant and will aid absorption of nutrients [10].

Applications of antibacterial compounds in the food industry, antimicrobial compounds have potential to use as biopreservatives and bioinsecticides and also they have a potential for developing genetically modified crop plants with increased disease resistance. Application of plant antimicrobial compounds for controlling growth for foodborne pathogens is having the range of activity against the microorganisms [11]. Antibacterial agent depends on its use and its effectiveness. The US Food and Drug Administration regulates antibacterial soaps and antibacterial substances [12].

\section{METHODS}

\section{Saponin extraction}

A. indicum leaves were collected from Vellore district. The leaves were washed with the distilled water for about two to three times, and then, it was cut into small pieces and shade dried for several days. The leaves were grounded using motor and pestle and stored in an airtight container. The powered leaves were mixed in methanol and acetone in the ratio $1: 5(\mathrm{~V} / \mathrm{V})$ to extract saponins. $10 \mathrm{ml}$ of the solvent was added to $1 \mathrm{~g}$ of the power and it was allowed to soak in the solvent for about $24 \mathrm{hrs}$. Then, the mixture was subjected to centrifugation at $2000 \mathrm{rpm}$ for 10 minutes at $4^{\circ} \mathrm{C}$. The mixture was filtered using sterile Whatman's filter paper number 1 , and then, solvent was filtered again using syringe filter containing $0.2 \mu$ cellulose acetate membrane [13].

Gas chromatography-mass spectrometry (GS-MS) analysis GC was performed in VIT sophisticated analytic lab. $5 \mathrm{mg}$ of crude saponin extract (CSE) was dissolved in $1 \mathrm{ml}$ of methanol and was analyzed in GC-MS. The instrument used was GC-MS JEOL (GCMATE II GC-MS, Agilent Technologies 6890N Network GC system for GC). The 
column (HP5) was fused silica $50 \mathrm{~m} \times 0.25 \mathrm{~mm}$. Analysis conditions were 20 minutes at $100^{\circ} \mathrm{C}, 3$ minutes at $235^{\circ} \mathrm{C}$ for column temperature, $240^{\circ} \mathrm{C}$ for injector temperature, helium was the carrier gas and split ratio was $5: 4$. The sample $(1 \mu \mathrm{l})$ was evaporated in a splitless injector at $300^{\circ} \mathrm{C}$. Run time was 30 minutes. The compounds were identified by GC coupled with MS. The molecular weight and structure of the compounds were ascertained by matching with reference compounds available in the National Institute Standard and Technology [14].

\section{Agar well diffusion assay (antimicrobial susceptibility test)}

Antimicrobial activity of the sample was determined using agar well diffusion method. $20 \mathrm{ml}$ of sterile nutrient broth was prepared and dispensed into four different test tubes, such that each containing $5 \mathrm{ml}$ of broth. To each of the test tube, $0.1 \mathrm{ml}$ of four different strainsStaphylococcus aureus (MTCC: 3160) and Escherichia coli (MTCC: 443) was inoculated and incubated overnight. Meanwhile, $150 \mathrm{ml}$ of MuellerHilton Agar was prepared and is it carefully poured into four different Petri plates. After solidification, four different pathogen cultures were uniformly spread using cotton swab (lawn culture). Wells of about $6 \mathrm{~mm}$ in diameter was punched using cork borer. Then, the well was loaded with $100 \mu \mathrm{l}$ extract (which was resuspended in the dimethyl sulfoxide [DMSO] solvent). DMSO was used as negative control and streptomycin was used as positive control. The inoculated plates were, then, incubated at $37^{\circ} \mathrm{C}$ for about $24 \mathrm{hrs}$. The plates were further observed for the presence of the zone of clearance around the wells. The size of the zone obtained was measured and the antimicrobial activity obtained was measured in term of the average diameter of zone of inhibition in millimeter. This enables to compare with the standard antibiotics [15].

\section{Minimum inhibitory concentration (MIC)}

MIC of the CSE was identified using the 96-well plate method. Pathogenic microbes were grown in 96-well ELISA plates and were treated with serially diluted CSE. The growth of microorganisms was observed in ELISA reader by checking the turbidity. The microorganisms used in this study are E. coli (MTCC: 443) and S. aureus (MTCC: 3160).

\section{2,2-diphenyl-1-picrylhydrazyl (DPPH) reduction assay}

DPPH solution of $1 \mathrm{mg} / \mathrm{ml}$ concentration dissolved in methanol was used for this study. $200 \mu \mathrm{l}$ of DPPH solution was added to all the test tubes. 100 $\mu \mathrm{l}$ of methanol was used as blank. $100 \mu \mathrm{l}$ of ascorbic acid $(1 \mathrm{mg} / \mathrm{ml})$ was used as standard, $100 \mu \mathrm{l}$ of CSE at varying concentrations $(0.25 \mathrm{mg} / 0.1 \mathrm{ml}$ to $2.5 \mathrm{mg} / 0.1 \mathrm{ml}$ ) was used as test. These tubes were incubated then incubated in the dark region for about 30 minutes. Then, absorbance was observed in an ultraviolet spectrophotometer at $517 \mathrm{~nm}$. The radical scavenging activity (inhibition of DPPH free radical in percent) was calculated using the following formula: \% inhibition=([Ac-At]/Ac)*100. Where Ac: Absorption of the blank sample; At: Absorption of the test sample. Percentage of inhibition concentration was calculated from the graph plotting inhibition percentage against extract concentration [16].

\section{Comet assay}

About $0.5 \%$ agarose was prepared and uniformly spread on glass slide and allowed to form gel at $4^{\circ} \mathrm{C} .40 \mu \mathrm{l}$ of bacterial suspension was mixed with $40 \mu \mathrm{l}$ of $0.1 \%$ low melting agarose. The mixture was loaded onto the well punctured in the gel in glass slide. Lysis was carried out in $2.5 \mathrm{M} \mathrm{NaCl}$, 10 mM Na2EDTA (ph 8), 10 mM Tris-HCl (ph 8), 1\% of N-lauroylsarcosine sodium salt, $1 \%$ of Triton X-100, and $10 \%$ DMSO for 5 minutes. Electrophoresis was performed. The slides were then dehydrated with $70 \%$ of ethanol for 5 minutes and dried at room temperature

\section{RESULTS}

\section{GC-MS}

GC-MS analysis results are tabulated in Table 1. Total of 11 different components were detected and tabulated. The major saponin component present in the mixture was identified as benzene, 1,4-bis(phenylmethyl), found at 21.25 retention time, with a molecular weight of $258 \mathrm{~g} / \mathrm{mol}$.

\section{Agar well diffusion}

The investigation was carried on two Gram-negative pathogens, i.e., S. aureus and E. coli. CSE produced a zone of inhibition of $17 \mathrm{~mm}$ (S. aureus) and $15 \mathrm{~mm}$ (E. coli). Fig. 1 shows that $2 \mathrm{mg}$ of CSE produced $17 \mathrm{~mm}$ ZoI against $S$. aureus which is almost equal to the positive control streptomycin (10 mg).

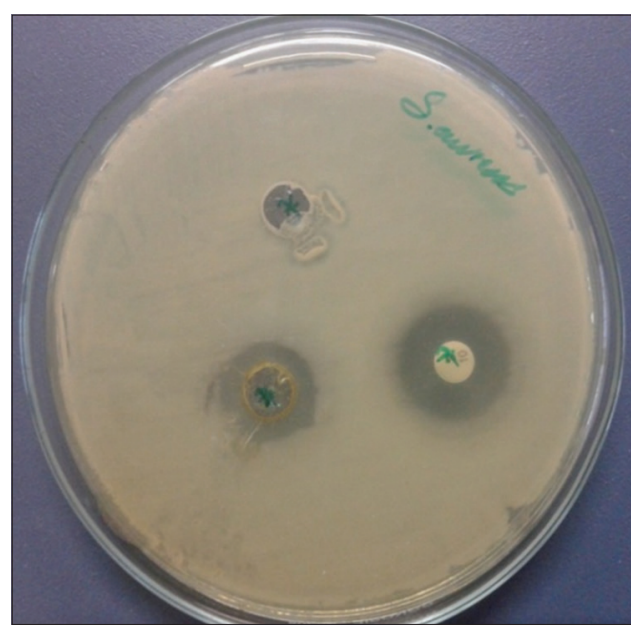

Fig. 1: Zone of inhibition for Staphylococcus aureus

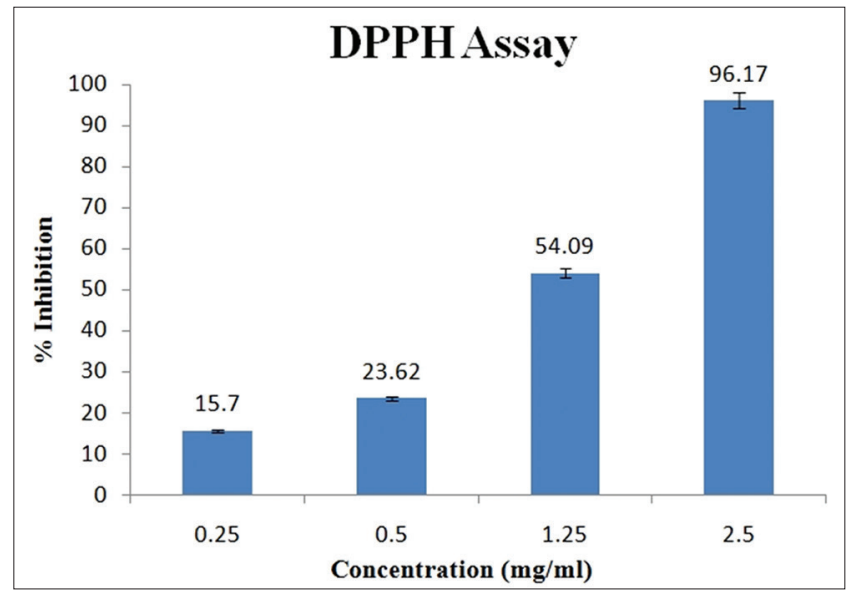

Fig. 2: 2,2-diphenyl-1-picrylhydrazyl assay for antioxidant activity of crude saponin extract

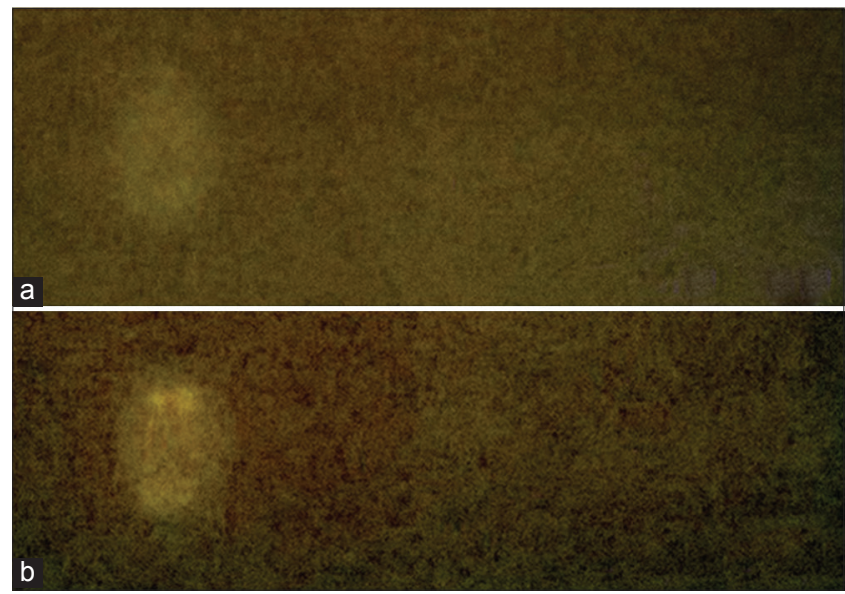

Fig. 3 Comet assay results (a: Negative control, b: Sample) 
Table 1: GC-MS analysis of crude saponin extract

\begin{tabular}{|c|c|c|c|c|c|c|}
\hline \multirow[t]{2}{*}{ RT } & \multicolumn{2}{|c|}{ Reference similarity } & \multirow[t]{2}{*}{ Name of the compound } & \multirow{2}{*}{$\begin{array}{l}\text { Molecular } \\
\text { weight }\end{array}$} & \multirow{2}{*}{$\begin{array}{l}\text { Observed } \\
\text { molecular } \\
\text { weight }\end{array}$} & \multirow[t]{2}{*}{ Structure } \\
\hline & $\operatorname{Rev}$ & For & & & & \\
\hline 10.41 & 727 & 207 & N-Acetyl-N-desmethylmethoxyphenamine & 207 & 206.9 & \\
\hline 12.52 & 873 & 524 & Diphenylmethane & 168 & 280.9 & \\
\hline 14.82 & 798 & 594 & Cathinone & 149 & 182.1 & \\
\hline 17.11 & 966 & 897 & 3,7,11,15-tetramethyl-2-hexadecen-1-OL & 296 & 318.9 & \\
\hline 17.86 & 912 & 687 & $\begin{array}{l}\text { 7,9-di-tert-butyl-1-oxaspiro }(4,5) \\
\text { deca-6,9-diene-2,8-dione }\end{array}$ & 276 & 309.3 & \\
\hline 18.32 & 891 & 624 & 1,2-benzenedicarboxylic acid, butyl octyl ester & 334 & 429.5 & \\
\hline 19.11 & 774 & 469 & 1,3,6-heptatriene, 2,5,5-trimethyl & 136 & 281.1 & \\
\hline 21.25 & 887 & 613 & Benzene, 1,4-bis (phenylmethyl)- & 258 & 281.1 & \\
\hline 24.64 & 810 & 414 & Octadecane, 9-ethyl-9-heptyl & 380 & 283.1 & \\
\hline
\end{tabular}

GC-MS: Gas chromatography-mass spectrometry

Minimal inhibitory concentration (MIC)

CSE demonstrated a significant MIC of $1.11 \mathrm{mg} / \mathrm{ml}$ concentration against $S$. aureus and E. coli.

\section{Antioxidant assay (DPPH reduction assay)}

CSE demonstrated increasing percentage of antioxidant activity, with lowest inhibition of $15.7 \%$ at $0.25 \mathrm{mg} / \mathrm{ml}$ concentration, to a maximum of $96.17 \%$ inhibition at $2.5 \mathrm{mg} / \mathrm{ml}$ concentration. Fig. 2 shows the graphical representation of the DPPH assay results.

\section{Comet assay}

Comet assay showed no formation of comet tail, indicating that the CSE did not cause any DNA damage at MIC concentration $(1.11 \mathrm{mg} / \mathrm{ml})$ Fig. 3 shows the gel image of comet assay for control and test group.

\section{CONCLUSION}

Based on the results obtained from this work, it is evident that the CSE from $A$. indicum leaves has potential for biological applications as an antibacterial agent and also as an antioxidant agent. Although further in vivo studies and toxicity studies are required to confirm this report, a significant antibacterial activity similar to that of the standard antibiotic, with a significant MIC value at $1.11 \mathrm{mg} / \mathrm{ml}$, and also an excellent antioxidant activity at $2.5 \mathrm{mg} / \mathrm{ml}$ concentration are strong proof of its biological activity of CSE from A. indicum leaves.

\section{REFERENCES}

1. Kannabiran K, Mohankumar T, Gunaseker V. Evaluation of antimicrobial activity of saponin isolated from Solanum xanthocarpum and Centella asiatica. Int J Natl Eng Sci 2009;3(1):25-8.

2. Mohite MS, Shelar PA, Raje VN, Babar SJ, Sapkal RK. Review article on pharmaceutical properties of Abutilon indicum. Asian J Pharm Res 2012;2(4):156-60.

3. Abdul MM, Sarker AA, Saiful IM, Muniruddi A. Cytotoxic and antimicrobial activity of crude extract of Abutilon indicum. Int Pharmacogn Phytochem Res 2010;2(1):1-4.

4. Khadabadi SS, Bhajipale NS. Review on some important medicinal plants of Abutilon species. Res J Pharm Biol Chem Sci 2010;1(4):718-29.

5. Singh R, Mendhulkar V. Abutilon indicum (Linn.) Sweet leaves, a natural source of saponin: A spectrophotometric assay. Int J PharmTech Res 2015;2(1):1-4.

6. Cheok CY, Salman HA, Sulaiman R. Extraction and quantification of saponins: A review. Food Res Int 2014;59:16-40. 
7. Hostettmann K, Marston A. Chemistry of Pharmacology of Natural Compounds. Saponin. Cambridge: Cambridge University Press; 1995. p. $212,233$.

8. Cornell University-College of Agriculture and Life sciences. Department of Animal Science: Plants Poisonous to Livestock. Available from: http:// www.poisonousplants.ansci.cornell.edu/toxicagents/saponin.html.

9. Hembree JC. Medical Marijuana. Benefits of Saponin. Available from: https://www.medicalmarijuana.com/benefits-of-saponins/.

10. Marciano M. The Naturopathic Herbalist. Saponins. Available from: http://www.thenaturopathicherbalist.com/plant-constituents/saponins/.

11. Hintz T, Mathews KK, Di R. The use of antimicrobial compound for food preservation. Biomed Res Int 1995;36(3-4):267-77.

12. APUA. General Background: Antibiotic Agents. Available from: http:// www.tufts.edu/med/apua/about issue/agents.html

13. Thanigaiarassu RR, Kannabiran K, Gopieshkhanna V. Antibacterial activity of saponin isolated from the leaves of Solanum trilobatum Linn. J Appl Biol Sci 2008;2(3):109-12.

14. Razia M, Sowmiya R, Lavanya K, Karthiga V, Bernala W, Deboral P. GC-MS, FTIR and in vitro antibacterial activity of Abutilon indicum. Int J Biol Pharm Res 2013;4(4):256-60.

15. Mateen A, Suresh PV, Ahmed P. Evaluation of antibacterial activity of Cuscuta reflexa and Abutilon indicum. Int J Pharm Biol Sci 2011;2(4):355-61.

16. Reddy SK, Krishna M, Sahoo D, Mallick J. In vitro antioxidant activity of ultra-sonic bath assisted ethanol extract of Abutilon indicum leaf. Int J Pharm Dev Technol 2012;2(2):77-9. 